\title{
Review and Prospect on Interactional Justice
}

\author{
Liangtie Dai, Haixin Xie \\ Management School, Jinan University, Guangzhou, China \\ Email: 422672998@qq.com
}

Received 7 December 2015; accepted 15 January 2016; published 20 January 2016

Copyright (C) 2016 by authors and Scientific Research Publishing Inc.

This work is licensed under the Creative Commons Attribution International License (CC BY).

http://creativecommons.org/licenses/by/4.0/

(c) (i) Open Access

\begin{abstract}
Different from distributive and procedural justice, interactional justice refers to the perception of equity in the relationship between supervisors and employees, which is the most recent advance in the justice literature. This paper first gave a brief introduction to the development and formation of the definition of interactional justice as well as its measurement. Then it examined the antecedent variables of interactional justice from leaders and subordinates' perspectives and the outcome variables of interactional justice from the individual and organizational levels. Finally, it pointed out the limitations of current studies based on the overview and accordingly indicated that future research should integrate interactional justice to the study of leadership behavior, explore the integration mechanism of antecedent variables and outcome variables and strengthen the local research of interactional justice.
\end{abstract}

\section{Keywords}

Interactional Justice, Antecedent Variables, Outcome Variables

\section{Introduction}

Fairness has been the topic that attaches people’s attention historically. Social-level fairness concerns the impartiality and rationality of social order while the organizational-level fairness concerns certain aspects of organization management, like distribution and incentives, which exerts great influence on the effectiveness and competition of the organization. The perception of fairness can be seen as a motive for people's behavior in organization. It has been proved that the perception of fairness can give rise to positive feelings and behaviors of employees, like job satisfaction, trust and organization citizenship behavior and so on [1]. So it is of great theoretical and practical significance to study fairness.

Previously most of the studies have focused on the study of distributive and procedural justice. And researchers have become more and more interested in interactional justice, which emphasizes the relationship quality between leaders and subordinates. To our knowledge, leaders, as key characters in the organization, play an im- 
portant role in influencing the attitudes and behaviors of employees as well as the operation of the organization. So the good relationship between leaders and subordinates can yield many expected or unexpected positive outcomes. That is to say, as one of the indicators of leader-subordinate relationship, interactional justice may play a unique part in organization, especially in the context of China laying stress on Guanxi and Mianzi.

Based on the existing literature on interactional justice, this paper analyzes and summarizes the definition, measurement, antecedent variables and outcome variables of interactional justice and then points out research directions for future study.

\section{Definition of Interactional Justice}

The theory of interactional justice has been developed and deepened continually along with the development of the theory of organizational justice. In the past, many researchers devoted themselves to explore the definition and dimension of justice and achieved fruitful results. At the beginning, researchers highlighted distributive justice which meant that individuals would consider the ratio of their input and output and then compare their contributions and gainings. Adams (1965) [2] first put forward the equity theory, suggesting that when perceiving the fairness of the results, individuals would work out the ratio of their input and output and compare their distributive results with themselves (internal and external) and others. After this procedure, individuals would make the conclusion whether the distribution was fair or not. Subsequently, some researchers argued that distributive justice neglected procedures used to determine outcome distributions or allocations. So they changed the research direction to the executive routine of the distribution. Thibaut and Walker [3] brought out the concept of procedural justice, believing that the determining factor for fairness perception was not the final distributive results but the procedure of plan and the carrying out of decisions. After studying the satisfaction of the litigators with the trial results and the perception of fairness of the litigators in the process of trial during different judicial trial process, they proposed two important concepts related to procedural justice: process control and decision control. In keeping with this view, Leventhal et al. [4] suggested six criteria about procedural justice, which were consistency rule, representativeness rule, bias suppression rule, accuracy rule, correctability rule and ethicality rule. A procedure should meet these criteria to see if it was to be perceived as fair. From the above we can see that organizational justice includes two basic dimensions: distributive justice and procedural justice.

On the basis of previous studies, Bies and Moag [5] introduced the concept of interactional justice, addressing that interactional justice was primarily concerned with the interaction ways among people and the perception of justice and emphasizing that the employee's perception of justice in the process of procedure execution would be influenced by the attitude of the executors towards them and how the executors treated them. Accordingly, Greenberg [6] [7] divided interactional justice into two parts: interpersonal justice and informational justice, of which the former referred to whether executors treated their employees with politeness and respect in executing procedures and deciding the results and the latter referred to whether executors delivered related information to employees, whether they explained to the employees why they adopted certain distributive procedure and why the distributive results turned out like that. Since Bies and Moag brought out the concept of interactional justice, researchers kept expanding studies in this field and also brought out the concept of interactional justice from different angles. For instance, Bradley and Sparks [8] defined interactional justice as the attitudes and behaviors of the exchangers. Ando and Matsuda [9] thought that interaction justice was defined as the feelings of employees about how they were treated in the process of procedure execution. When employees felt that they were treated with fairness by their leaders, they would feel passionate and have high morale.

Most of the researchers didn't study interactional justice solely and saw it as a part of procedural justice before Bies and Moag brought out the concept of interactional justice. In fact, there are significant correlations and distinctions among distributive justice, procedural justice and interactional justice. They can be seen as the three dimensions of organizational justice. However, specifically distributive justice puts more emphasis on the distributive results and the impartiality and rationality of the reward; procedural justice puts more emphasis on the process of decision-making and whether the two-way communication exists between executors and subordinates; interactional justice puts more emphasis on the quality of the interpersonal communication among people, like the way of communication between them is appropriate or not.

In summary, we provide a brief introduction to the development and formation of the definition of interactional justice. At present, most of the studies adopted the definition brought out by Greenberg. 


\section{Measurement of Interactional Justice}

As interest in interactional justice increases, the measurement approaches used to study it have proliferated. The study on the scale development of interactional justice has gained success and the most representative scales are scales developed by Moorman [10], Niehoff \& Moorman [11], Colquit [12] and Liu Ya, Long Lirong and Li Ye [1].

When developing the scale of interactional justice, Moorman [10] suggested that the scale should not only emphasize the full and sincere explanation of the executors but also emphasize whether the executor considered the employees' opinions and controlled their own prejudice, both of which could influence the employees' perception of fairness. The final version of the scale developed by Moorman included six items and had high reliability after empirical analysis.

When designing the scale of interactional justice, Niehoff and Moorman [11] mainly made their considerations according to two aspects: one was that the perception of employees about the degree to which leaders consulted the demands of employees and the other one was that whether leaders could offer rational explanation about the related distributive results to employees. The final version of the scale was composed of nine items and the reliability coefficient was 0.92 after examined.

As to the measurement means of interactional justice, most of the researchers adopted indirect measurement mode. After conducting a meta-analysis about organizational justice of 183 organizations in 25 years, Colquitt et al. [13] found out that indirect measurement mode had more close relationship with outcome variables and had better effect on management suggestions. Bies and Moag [5] demonstrated four principles about the measurement of interactional justice, including respect, propriety, justification and truthfulness. Based on that, Colquitt [12] compiled the scale of interactional justice, which was composed of four items about interactional justice and five items about informational justice. The scoring method was Likert five points method. A lot of studies have verified the good reliability and validity of the scale with over 0.9 coefficient of internal consistency [14] [15]. The scale developed by Colquitt is mostly used in the measurement of interactional justice at present.

Researchers Liu Ya, Long Lirong and Li Ye [1] developed a four-factor scale about organizational justice in the context of Chinese culture. In this scale, interactional scale was divided into leadership justice and informational justice with ten items, of which six measured leadership justice and four measured informational justice. The results of empirical analysis showed that the reliability coefficient of these two scale were 0.90 and 0.89 respectively.

In the study of interactional justice, researchers will decide whether they divide international justice into one dimension or two dimensions based on the need of their research or the results of factor analysis.

\section{Antecedent Variables and Outcome Variables of Interactional Justice}

\subsection{Antecedent Variables of Interactional Justice}

What promotes perceptions of interactional justice? We have mentioned the four principles of interactional justice proposed by Bies and Moag: respect, propriety, justification and truthfulness. Scott et al. [16] noted that in the process of internal communication in the organization, the degree to which the behaviors of the information senders, superiors or leaders, conformed to these four principles would influence the perception of interactional justice of the information receivers, the subordinates. Therefore, the perception of interactional justice is both influenced by the information senders and information receivers, who communicate with each other. To be specific, the personality and behaviors of leaders and subordinates will both engender influence on the subordinates' perception of interactional justice.

\subsubsection{The Influence of Leader Factors on Perception of Interactional Justice}

As to the antecedent variables of leader factors about the perception of interactional justice, the personality and behaviors of leaders are most studied by researchers. The performance of the leader, who is the source of communication process, will have direct influence on the perception of interactional justice. Mayer et al. [17] have attempted to address the relationship between leaders' personality and justice climate and they proved that among the Big-Five personalities, agreeableness of leaders was positively correlated with the perception of interactional justice while neuroticism of leaders was negatively correlated with the perception of interactional justice after the matching experiment of leaders and subordinates. At the same time, they found that the other three 
dimensions of Big-Five personalities, extraversion, conscientiousness and openness, were not significantly correlated with the perception of interactional justice. In the aspect of leader behaviors, $\mathrm{Li}$ and other scholars [18] reported that authentic leaders inclined to show more self-disclosure practices which could make their subordinate feel that they were liked and trusted by their leaders. As a result, the subordinate's perceptions of interactional justice would increase. Wang and Jiang [19] found that when abusive supervisors displayed hostile verbal and nonverbal behaviors, their subordinates would receive emotional and psychological mistreatment from them, which triggered the decreasing interactional justice of the subordinates.

\subsubsection{The Influence of Subordinate Factors on Perception of Interactional Justice}

During the process when leaders communicate with their subordinates, in addition to the role behaviors of leaders that can influence the perception of interactional justice, subordinates themselves also play a part. When leaders exert their influence, subordinates are not passive receivers any more. There are evidences that prove the close relationship between the personality and behavior of subordinates and the perception of interactional justice. For example, Scott, Colquitt and Zapata-Phelan [16] dealt with whether the personality characteristics of subordinates would influence the degree to which the seniors abode by the justice rules with 181 employees from one insurance company as their research subjects. The result showed that the personality characteristics of subordinates could significantly predict the perception of interactional justice but were not significantly correlated with informational justice. As to the behavioral characteristics of subordinates, Korsgaard et al. [20] found out after experiment research that the assertive behavior of employees would significantly make the leaders show more fair behavior, which could improve their perception of interactional justice.

So far we introduce the influence of leader and subordinate characteristics on the perception of interactional justice and we can see that studies on the antecedent variables of interactional justice are far from enough. The exploration on antecedent variables of interactional justice concerns the cultivation and improvement of employees' perception of interactional justice, which has great theoretical and practical significance, especially in organizational settings. So future studies should further verify the relationship between the perception of interactional justice and its antecedent variables. What is more, future studies should explore new variables in order to enrich the theory of the perception of interactional variables, like the similarity between leaders and their subordinates. Based on the principle of similarity and attraction, Tsui and Reilly [21] thought that the similarity of demography variables like age, gender, working periods and education between leaders and their subordinates would influence the attitudes and behaviors of both of them. Therefore, the degree to which leaders abide by the rules of interactional justice and the employees' perception of interactional justice is influenced by the similarity between them. Scott et al. [16] found that the similarity of gender and age between leaders and subordinates could significantly predict the perception of interactional justice and informational justice. Indeed it deserves the attention of researchers in terms of their implications for future research on interactional justice.

\subsection{Outcome Variables of the Perception of Interactional Justice}

Then what is the influential effect of interactional justice? Researchers have done a lot of empirical studies on the outcome variables of the perception of interactional justice. To summarize the current literature, this paper explores the outcome variables of interactional justice from the individual and organizational level.

\subsubsection{The Perception of Interactional Justice and Individual-Level Outcome Variables}

After conducting a meta-analysis of organizational justice, Colquitt et al. [13] divided the outcome variables of organizational justice into eleven types of variables. Among them, it proved that there was a strong relationship between interactional justice and agent evaluation of authority and job satisfaction and a rather weak relationship between interactional justice and job performance, organizational commitment and withdrawal behavior of employees. In addition, Cohen-Charash and Spector [22] also conducted a meta-analysis of organizational justice and the result showed that there were eight kinds of outcome variables about organizational justice. Some of the findings were proved to be the same as the research result of Colquitt et al., like the perception of interactional justice correlated strongly with agent evaluation of authority and job satisfaction while correlated weakly with job performance. However, some of the findings turned out to be different from the result of Colquitt et al., like the research conducted by Cohen-Charash and Spector showed a moderate correlation between the perception of interactional justice and organizational commitment and withdrawal behavior of employees. Moreover, with the continuing development of the theory of interactional justice, more and more researchers start to carry 
out related studies. For example, Ambrose and Schminke [23] illustrated that the perception of interactional justice had close relationship with the trust of the seniors. Ando and Matsuda [9] explored how the perception of interactional justice influenced the employees' role definition and their study showed that the perception of interactional justice could enlarge their role definition and then increased the organizational citizenship behavior of employees. In addition, Otto and Mamatoglu [24] explored the impact effect of interactional justice on the basis of social exchange theory with an investigation on 218 employees from the electronic information industry. The result showed that the perception of interactional justice could increase the organizational commitment of employees and decrease the turnover intention through the employees' perception of social support.

In addition to positive behaviors, interactional justice has been examined to be linked with negative behaviors. Le Roy, Bastounis and Poussard [25] in their study found that low perceived interactional justice was significantly related to higher counterproductive work behavior from individuals. In other words, when perceiving low interactional justice, individuals would engage in more active and passive counterproductive work behavior.

\subsubsection{The Perception of Interactional Justice and Organizational-Level Outcome Variables}

Interactional justice mainly involves the association and communication between employees and the administrators, which leads to the lack of the exploration on the high-level of outcome variables. In spite of this, a large number of studies have sought to link justice perceptions to a variety of organizational outcomes. Lu [26] explored how interactional justice influenced the conflict and attachment among cooperative enterprises from different countries. The study found out that interactional justice not only had positive influence on the attachment between enterprises and enterprises, but also could reduce the negative influence brought by cultural difference to enterprises. Luo [27] integrated the theory of fairness and strategic alliances to explore the influence of distributive justice, procedural justice and interactional justice on organization alliance performance. The result revealed that high level of interactional justice could increase the unity between top managers, which could further improve the alliance performance. What is more, other researchers also conducted the related research on the perception of fairness and alliance formation. Ariño and Ring [28] explored how the perceptions of fairness types shaped the partners' decision-making logics and they found out that informational justice and interactional justice could make the partner focus more on relationship quality and then influenced partners' evaluations of efficiency and equity of the proposed alliance, which in turn was helpful to let partners make the decision to form alliance.

To be summarized, efforts to explain the predictive effect of interactional justice on attitudinal and behavioral outcome variables are paying off which is beneficial for us to learn the significance of interactional justice. However, among the study of interactional justice's outcome variables, studies on organizational-level outcome variables are far less compared with individual-level outcome variables. High-level studies require researchers to look at things from a macroscopical angle and the specific interacting mechanism between variables and variables are more conceptual and abstract. Future studies can strengthen the influence of interactional justice on the strategic cooperation relationship between cooperative teams, organization departments and enterprises.

\section{Limitations and Prospects}

\subsection{Integrate Interactional Justice to the Study of Leader Behavior}

Organizational justice has always been the heated topic in regular organization activities and previous studies have proved the close relationship between interactional justice and employees' positive working attitudes, trust on leaders, organizational commitment and job performance [13], from which we can see that employees and enterprises pay much attention on fairness. If employees feel treated fairly by leaders, they will show much more positive attitudes and do more behaviors beneficial to the development of organization. In this process, the leader plays a key role as the one who communicates with the employees most. Bies [29] suggested the integration of the theory of fairness to the theory of leadership behaviors. Some studies have found the direct or indirect influence of employees' perception of interactional justice on the acceptance of the leaders' behaviors [30]. Hence, the study on the integration of interactional justice and leader behavior can not only enrich the theory of both of them, but also bring inspiration to the management of enterprises.

\subsection{Explore the Integration Mechanism of Antecedent Variables and Outcome Variables}

After literature review, we find that most of the researches study the antecedent variables and outcome variables 
of interactional justice separately and few of them bring them into an integrated framework to make systematic theory construction. Because of the diversity in antecedent variables and outcome variables, interactional justice is a field in need of integration. Therefore, future study should on one hand figure out the moderation and mediation role of interactional justice in some key antecedent variables and outcome variables and on the other hand investigate the mediation and moderation mechanism between interactional justice and antecedent variables as well as the mediation and moderation mechanism between interactional justice and outcome variables. In any event, much attention should be attached to the integration mechanism of interactional justice.

\subsection{Strengthen the Local Research of Interactional Justice}

The related research results from western countries can't be directly applied to China due to the difference between the culture background of east and west. So carrying out the study on interactional justice under the Chinese culture background is very important and urgent. Under the impact of individualism and rational thinking, communication style of western society focuses on the consideration of individual itself and puts less care on the surrounding interpersonal relationship. In this way, although they seem to be unkind to each other, they actually have mutual trust on each other because they are protected by laws. However, things are different from China. Influenced by Confucianism, Chinese people not only take consideration of the surrounding interpersonal relationship, but also concern the social power structure. So before carrying out the local study of interactional justice, future studies need to answer these two questions: how Chinese people define interactional justice and how to measure the perception of interactional justice of Chinese people. Taken together, in the future, researchers should explore the principles of interactional justice in Chinese people and then compile the scale of interactional justice fit for Chinese people to help this field enter a more mature stage.

\section{References}

[1] Liu, Y., Long, L.R. and Li, Y. (2003) The Influence of Organizational Justice on Organizational Effectiveness Variables. Management World, 5, 126-132.

[2] Adams, J.S. (1965) Inequity in Social Exchange. Advances in Experimental Social Psychology, 2, 267-299. http://dx.doi.org/10.1016/S0065-2601(08)60108-2

[3] Thibaut, J.W. and Walker, L. (1975) Procedural Justice: A Psychological Analysis. L. Erlbaum Associates, Hillsdale.

[4] Leventhal, G.S., Karuza, J. and Fry, W.R. (1980) Beyond Fairness: A Theory of Allocation Preferences. Justice and Social Interaction, 3, 167-218.

[5] Bies, R.J. and Moag, J.S. (1986) Interactional Justice: Communication Criteria of Fairness. Research on Negotiation in Organizations, 1, 43-55.

[6] Greenberg, J. (1990) Organizational Justice: Yesterday, Today, and Tomorrow. Journal of Management, 16, $399-432$. http://dx.doi.org/10.1177/014920639001600208

[7] Greenberg, J. and Cropanzano, R. (1993) The Social Side of Fairness: Interpersonal and Informational Classes of Organizational Justice. In: Justice in the Workplace: Approaching Fairness in Human Resource Management, Lawrence Erlbaum Associates, Hillsdale.

[8] Collie, T., Bradley, G. and Sparks, B.A. (2002) Fair Process Revisited: Differential Effects of Interactional and Procedural Justice in the Presence of Social Comparison Information. Journal of Experimental Social Psychology, 38, 545-555. http://dx.doi.org/10.1016/S0022-1031(02)00501-2

[9] Ando, N. and Matsuda, S. (2010) How Employees See Their Roles: The Effect of Interactional Justice and Gender. Journal of Service Science and Management, 3, 281-286. http://dx.doi.org/10.4236/jssm.2010.32035

[10] Moorman, R.H. (1991) Relationship between Organizational Justice and Organizational Citizenship Behaviors: Do Fairness Perceptions Influence Employee Citizenship? Journal of Applied Psychology, 76, 845-855. http://dx.doi.org/10.1037/0021-9010.76.6.845

[11] Niehoff, B.P. and Moorman, R.H. (1993) Justice as a Mediator of the Relationship between Methods of Monitoring and Organizational Citizenship Behavior. Academy of Management Journal, 36, 527-556. http://dx.doi.org/10.2307/256591

[12] Colquitt, J.A. (2001) On the Dimensionality of Organizational Justice: A Construct Validation of a Measure. Journal of Applied Psychology, 86, 386-400. http://dx.doi.org/10.1037/0021-9010.86.3.386

[13] Colquitt, J.A., Conlon, D.E., Wesson, M.J., Porter, C.O.L.H. and Ng, K.Y. (2001) Justice at the Millennium: A MetaAnalytic Review of 25 Years of Organizational Justice Research. Journal of Applied Psychology, 86, 425-445. http://dx.doi.org/10.1037/0021-9010.86.3.425 
[14] Ambrose, M.L. and Schminke, M. (2009) The Role of Overall Justice Judgments in Organizational Justice Research: A Test of Mediation. Journal of Applied Psychology, 94, 491-500. http://dx.doi.org/10.1037/a0013203

[15] Spencer, S. and Rupp, D.E. (2009) Angry, Guilty, and Conflicted: Injustice toward Coworkers Heightens Emotional Labor through Cognitive and Emotional Mechanisms. Journal of Applied Psychology, 94, 429-444. http://dx.doi.org/10.1037/a0013804

[16] Scott, B.A., Colquitt, J.A. and Zapata-Phelan, C.P. (2007) Justice as a Dependent Variable: Subordinate Charisma as a Predictor of Interpersonal and Informational Justice Perceptions. Journal of Applied Psychology, 92, 1597-1609. http://dx.doi.org/10.1037/0021-9010.92.6.1597

[17] Mayer, D., Nishii, L., Schneider, B. and Goldstein, H. (2007) The Precursors and Products of Justice Climates: Group Leader Antecedents and Employee Attitudinal Consequences. Personnel Psychology, 60, 929-963. http://dx.doi.org/10.1111/j.1744-6570.2007.00096.x

[18] Li, F., Yu, K.F., Yang, J., Qi, Z. and Fu, J.H.Y. (2014) Authentic Leadership, Traditionality, and Interactional Justice in the Chinese Context. Management and Organization Review, 10, 249-273. http://dx.doi.org/10.1111/more.12027

[19] Wang, R. and Jiang, J. (2015) How Abusive Supervisors Influence Employees’ Voice and Silence: The Effects of Interactional Justice and Organizational Attribution. The Journal of Social Psychology, 155, 204-220. http://dx.doi.org/10.1080/00224545.2014.990410

[20] Korsgaard, M.A., Roberson, L. and Rymph, R.D. (1998) What Motivates Fairness? The Role of Subordinate Assertive Behavior on Manager's Interactional Fairness. Journal of Applied Psychology, 83, 731-744. http://dx.doi.org/10.1037/0021-9010.83.5.731

[21] Tsui, A.S. and O’Reilly, C.A. (1989) Beyond Simple Demographic Effects: The Importance of Relational Demography in Superior-Subordinate Dyads. Academy of Management Journal, 32, 402-423. http://dx.doi.org/10.2307/256368

[22] Cohen-Charash, Y. and Spector, P.E. (2001) The Role of Justice in Organizations: A Meta-Analysis. Organizational Behavior and Human Decision Processes, 86, 278-321. http://dx.doi.org/10.1006/obhd.2001.2958

[23] Ambrose, M.L. and Schminke, M. (2003) Organization Structure as a Moderator of the Relationship between Procedural Justice, Interactional Justice, Perceived Organizational Support, and Supervisory Trust. Journal of Applied Psychology, 88, 295-305. http://dx.doi.org/10.1037/0021-9010.88.2.295

[24] Otto, K. and Mamatoglu, N. (2015) Why Does Interactional Justice Promote Organizational Loyalty, Job Performance, and Prevent Mental Impairment? The Role of Social Support and Social Stressors. The Journal of Psychology, 149, 193-218. http://dx.doi.org/10.1080/00223980.2013.866535

[25] Le Roy, J., Bastounis, M. and Poussard, J.M. (2012) Interactional Justice and Counterproductive Work Behaviors: The Mediating Role of Negative Emotions. Social Behavior and Personality: An International Journal, 40, 1341-1355. http://dx.doi.org/10.2224/sbp.2012.40.8.1341

[26] Lu, Y. (2006) Toward the Micro and Macro-Level Consequences of Interactional Justice in Cross-Cultural Joint Ventures. Human Relations, 59, 1019-1047. http://dx.doi.org/10.1177/0018726706068769

[27] Luo, Y.D. (2007) The Independent and Interactive Roles of Procedural, Distributive, and Interactional Justice in Strategic Alliances. Academy of Management Journal, 50, 644-664. http://dx.doi.org/10.5465/AMJ.2007.25526452

[28] Ariño, A. and Ring, P.S. (2010) The Role of Fairness in Alliance Formation. Strategic Management Journal, 31, 10541087. http://dx.doi.org/10.1002/smj.846

[29] Bies, R.J. (2005) Are Procedural Justice and Interactional Justice Conceptually Distinct? Lawrence Erlbaum Associates Publishers, Hillsdale.

[30] van Knippenberg, D., De Cremer, D. and van Knippenberg, B. (2007) Leadership and Fairness: The State of the Art. European Journal of Work and Organizational Psychology, 16, 113-140. http://dx.doi.org/10.1080/13594320701275833 